\title{
THE CONCEPT OF USING A WEIGHTED AMPLITUDE TO DETERMINE THE FATIGUE LIFE OF LOAD STRESS BLOCKS
}

\author{
JUSTYNA OBRAє \\ Opole University of Technology, Faculty of Mechanical Engineering, Opole, Poland \\ e-mail: kijakjustyna@gmail.com
}

\begin{abstract}
This work shows the model for determining the fatigue life of block loads. The proposed model is a kinematic model that can be used using a linear fatigue characteristic, i.e. in the range of a large number of cycles. The model has been developed on the basis of the previous hypotheses of cumulation of damage by Palmgren-Miner using a weighted amplitude of $m$-degree. The final version proposes calculation of the variable amplitude of the average based on these two models.
\end{abstract}

Keywords: uniaxial load, damage, stress amplitude

\section{Introduction}

For a long time, a hypothesis of accumulation of fatigue failures has been sought by which it could be possible to accumulate fatigue damage in the case of non-constant-amplitude loads, often referred to as random ones. Palmgren (1924) first published a proposal for cumulation of fatigue failures, which was then improved and disseminated by Miner (1945). Over the years, many hypotheses have been created regarding the accumulation of damage, e.g. Bathias and Pineau (2010), Serensen et al. (1975) and Liu and Zenner (1993). These hypotheses describe relatively well the phenomenon of accumulation of fatigue damage for stationary runs. It is completely different for non-stationary loads such as block loads of different amplitudes. One of them is a two-level program called High-Low (H-L) and Low-High (L-H). Based on this, a further hypothesis was created by Marco and Starkey (1954) which distinguished between the load blocks, the number of cycles and the material constant characteristic of the material. All subsequent hypotheses of the accumulation of fatigue injuries were based on the idea of Palmgren-Miner, which was an improvement. Recent hypotheses have emerged, which take into account the memory of a material that remembers the history of charges. This solution is taken from a field far from the scientific sciences, namely psychology, the Ebbinghaus model (Ebbinghaus, 1913). The works (Böhm et al., 2014, 2016, 2020) describe the models in which the material memory is taken into account. On this basis, two models were developed: the exponential and the power one. The above new models relatively well describe the results of experimental studies. Unfortunately, these models cannot be used to predict fatigue life without knowing what fatigue life will be because the total number of failure cycles $N_{f}$ is required for calculation.

For many years, a model for presentation of test results is sought which could be used for loads other than those with fixed amplitudes. The first such a proposal was the Gassner model (Gassner, 1954), which took the characteristic maximum amplitude as its amplitude. However, on this assumption, waveforms of different statistical characteristics, including sinusoidal tests, could not be compared with each other. The recently intersic work on this subject was published by Skibicki et al. (2014). As a result, many authors proposed different models for determination of the substitute amplitude (Palmgren, 1924; Miner, 1945; Gassner, 1954). A more complete overview of different models for displaying variable amplitudes can be found in (Eagoda and 
Sonsino, 2004). This paper presents eight methods of presenting the results of fatigue tests for variable and constant amplitude loads. Some methods have proved to be suitable for presentation of variable- and fixed-amplitude studies, some of which have not. One of the promising methods is the average element of stage $n$ method, where $n$ is selected experimentally.

This model is characterized by the sum of all cycles that are greater than the amplitude limit of $\sigma_{a k}$ in the power of the Basquina characteristic

$$
\sigma_{a n}=\sqrt[m]{\frac{1}{N_{b}} \sum_{i} \sigma_{a i}^{m}} \quad \text { for } \quad \sigma_{a i}>a \sigma_{a k}
$$

here, in the case of loads applied by the sum of blocks

$$
N_{b}=n_{1}+n_{2}
$$

is the total number of cycles.

In view of the above, a model can be proposed that will remember the load history as the amplitude weighted from the time history to time and, therefore, accumulate damage on the ongoing basis. The aim of this work is, therefore, to propose a model that can be adopted as a kinematic model and used in a large number of cycles, where we have a linear fatigue strategy.

\section{The pattern of cumulation using a weighted amplitude}

Using the form of the Basquina characteristic (linear double logarithmic), the basic stress fatigue characteristic can be recorded as

$$
\sigma_{a}=\sigma_{f}^{\prime}\left(2 N_{f}\right)^{b}
$$

where: $\sigma_{a}$ - stress amplitude, $\sigma_{f}^{\prime}$ - fatigue factor of plastic strain, $2 N_{f}$ - number of load turns, $b=-1 / m-$ fatigue strength exponent.

According to linear summation of damage, the sum of the damage in the first block with the number of cycles $n_{1}$ and the amplitude of the strain $\sigma_{a 1}$ is given by the relationship

$$
d_{1}\left(n_{1}\right)={\frac{n_{1}}{N}}_{f 1}=2 n_{1}\left(\frac{\sigma_{f}^{\prime}}{\sigma_{1 a}}\right)^{m}
$$

According to the Palmgren-Miner hypothesis, the second block is obtained as

$$
d_{2}\left(n_{2}\right)=\frac{n_{1}}{N_{f 2}}=2 n_{2}\left(\frac{\sigma_{f}^{\prime}}{\sigma_{2 a}}\right)^{m}
$$

Bearing in mind partial damage (2.2) and (2.3), finally, the degree of the damage can be saved as

$$
D=d_{1}\left(n_{1}\right)+d_{2}\left(n_{2}\right)=1
$$

The formula determining the weighted amplitude of the stress amplitude according to Eq. (2.3) is as follows

$$
\sigma_{\text {aeqi }}=\sqrt[m]{\frac{n_{1} \sigma_{1 a}^{m}+i \sigma_{2 a}^{m}}{n_{1}+i}}
$$

In addition, a second model may be proposed, in which the arithmetic mean of the current amplitude $\sigma_{2 a}$ and the weighted amplitude of the degree $m, \sigma_{a e q i}$, Eq. (2.5), after the second level $i$ cycle can be used to accumulate the damage

$$
\sigma_{\text {aeqi }, \text { mean }}=\frac{\sigma_{a e q i}+\sigma_{2 a}}{2}
$$


Therefore, the damage rate after the $i$-th cycle is assumed as the expression for the weighted amplitude

$$
d_{1,2 i}=2 n_{1}\left(\frac{\sigma_{f}^{\prime}}{\sigma_{1 a}}\right)^{m}+\sum_{i=1}^{n_{2, c a l}} 2\left(\frac{\sigma_{f}^{\prime}}{\sigma_{1 a e q i}}\right)^{m}
$$

and the average amplitude

$$
d_{1,2 i}=2 n_{1}\left(\frac{\sigma_{f}^{\prime}}{\sigma_{1 a}}\right)^{m}+\sum_{i=1}^{n_{2, \text { cal }}} 2\left(\frac{\sigma_{f}^{\prime}}{\sigma_{1 \text { aeqi }, \text { mean }}}\right)^{m}
$$

In summary, if the severity of the $S_{1,2 i}$ damage reaches the value after the $i$-th cycle at the level two, according to the Palmgren-Miner (PM) rule

$$
d_{1,2 i}=D=1
$$

the expected number of cycles in the second block is expressed by

$$
n_{2, c a l}=i
$$

Figure 1 shows the interpretation of the equivalent amplitude variation for the H-L load as the number of cycle changes. As can be seen, the mean amplitude is between the amplitude obtained by the Palmgren-Miner hypothesis and the weighted degree $m$.

(a)

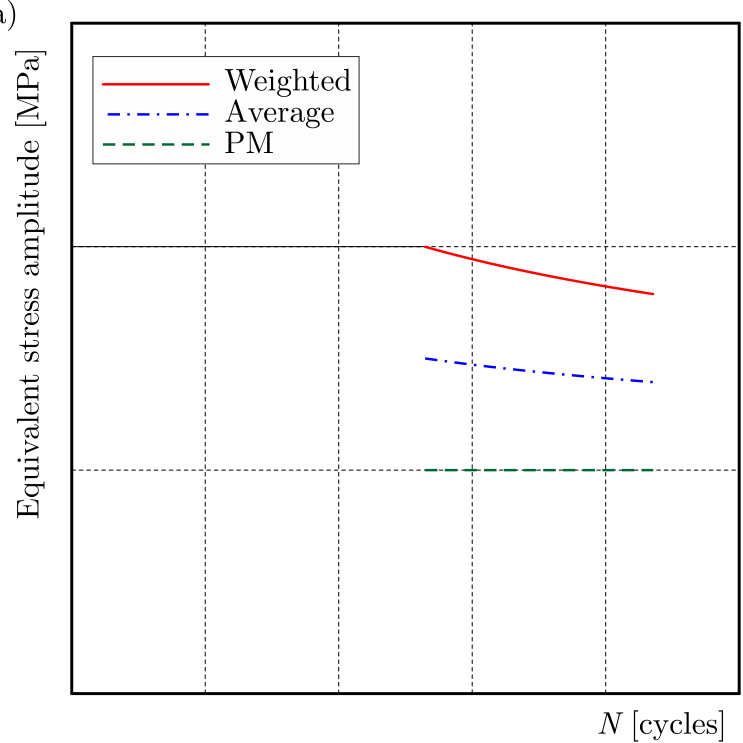

(b)

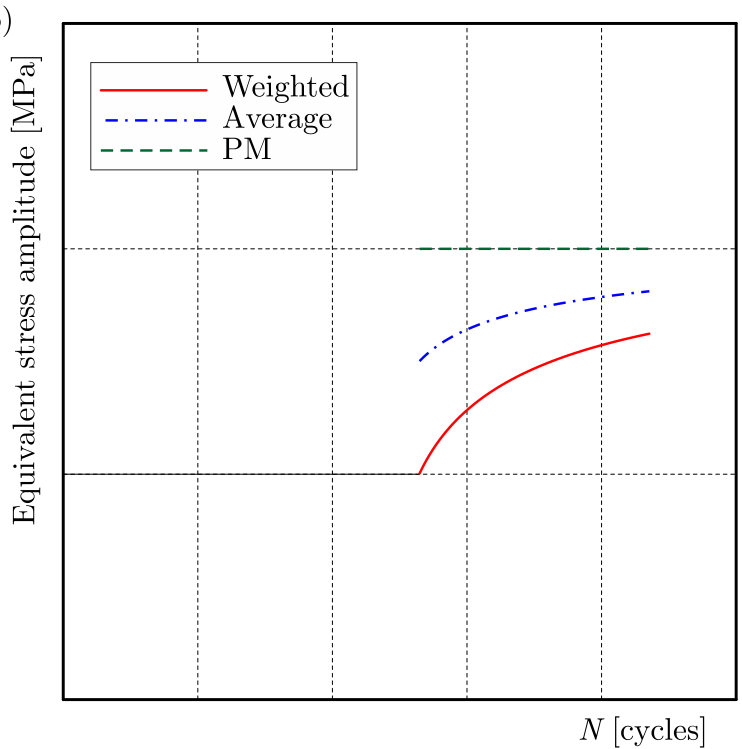

Fig. 1. Interpretation of the change in the amplitude equivalent to the load type (a) H-L and (b) L-H with a change in the number of cycles

\section{Conclusions}

- The proposed kinematic pattern of accumulation of damage uses the history of stress amplitudes, weighted amplitude over a given time, and the current peak amplitude.

- The model described must be verified on the basis of available and own experimental studies.

- It appears that the model can be determined for loads with linear characteristics, that is, for a range of high cycles or a small number of cycles with a small range of amplitude variations, where the characteristics can also be recorded in a linear pattern. 


\section{References}

1. Bathias C., Pineau A., Eds., 2010, Fatigue of Materials and Structures: Fundamentals, John Wiley, London: Hoboken, NJ

2. Böhm E., Kurek M., Junak G., Cieśla M., Łagoda T., 2014, Accumulation of fatigue damage using memory of the material, Procedia Materials Science, 3, 2-7

3. Böhm E., Kurek M., Łagoda T., Łagoda K., 2016, The use of a power law function for fatigue life estimation for block loads, Solid State Phenomena, 250, 1-9

4. Böhm E., KureK M., Łagoda T., 2020, Fatigue damage accumulation model of 6082-T6 aluminum alloy in conditions of block bending and torsion, Journal of Testing and Evaluation, 48, 6, 4416-4434

5. Ebbinghaus H., 1913, Memory: a contribution to experimental psychology, [In:] Classics in the History of Psychology, C.D. Green (Edit.), York University, Toronto, Ontario

6. Gassner E., 1954, Fatigue strength. A basis for assessment for structural parts with statistically changing operational loads (in German), Konstruktion, 6, 3, 97-104

7. LiU J., Zenner H., 1993, Calculation of the fatigue strength with multi-axis loading - Part 1 (in Germany), Materialwissenschaft und Werkstofftechnik, 24, 240-249

8. Łagoda T., Sonsino C.M., 2004, Comparison of different methods for presenting variable amplitude loading fatigue results, Materialwissenschaft und Werkstofftechnik, 35, 1, 13-20

9. Marco S.M., Starkey W.L., 1954, A concept of fatigue damage, Transactions of the ASME, 76, 627632

10. Miner M., 1945, Cumulative damage in fatigue, Journal of Applied Mechanics, 12, 159-164

11. Palmgren A.G., 1924, The life length of roller bearings or durability of ball bearings (in German), Zeitschrift des Vereines Deutscher Ingenieure (ZVDI), 14, 339-341

12. Serensen S.V., Kogayev V.P., Snajdorovic R.M., 1975, Bearing Capacity and Strength Calculation of Machine Parts (in Russian), Mashinostroenie, 3rd ed.

13. Skibicki D., Sempruch J., Pejkowski L., 2014, Model of non-proportional fatigue load in the form of block load spectrum, Materialwissenschaft und Werkstofftechnik, 45, 68-78

Manuscript received May 13, 2021; accepted for print May 31, 2021 